\title{
DOD JPADS PROGRAMS OVERVIEW \& NATO ACTIVITIES
}

\author{
Richard Benney, Joseph McGrath, Jaclyn McHugh, \\ Andrew Meloni, Greg Noetscher, Steve Tavan ${ }^{1}$ \\ US Army Research Development \& Engineering Command \\ Natick Soldier Research, Development and Engineering Center \\ Natick, MA 01760 \\ Sanjay Patel ${ }^{2}$ \\ Ignition Technology Inc. \\ Sudbury, MA 01776
}

The US Army Research Development and Engineering Command (RDECOM), Natick Soldier Research, Development and Engineering Center (NSRDEC) have teamed with all Department of Defense (DoD) services and organizations with interest in programs and investments in Joint Precision Airdrop System (JPADS) technology and systems. These organizations include: Office of the Secretary of Defense (OSD) to include: Joint Staff (JS); Acquisition, Logistics and Technology (ALT); Director of Defense Research and Engineering (DDR\&E), Advanced Systems and Concepts (AS\&C), Joint Forces Command (JFCOM), US Air Force Air Mobility Command (USAF AMC), USAF Air Mobility Warfare Center (AMWC), the US Army Product Manager Force Sustainment Systems (PM-FSS), US Marine Corps (USMC), US Transportation Command (TRANSCOM), US Special Operations Command (USSOCOM) and many other government agencies and contractors to plan and execute JPADS programs. This paper will provide an overview of some of the DoD JPADS programs to include: Results of the JPADS Advanced Concept Technology Demonstration (ACTD), recent Joint Military Utility Assessment (JMUA) \# 2, The US Army Formal Program of Record (PoR) for the JPADS Extra Light (700-2200lb capability), Rapid Combat Fielding (RCFs) Initiatives for JPADS 2,200lb systems and early results and lessons learned from Combat Operations, the recently started Wireless Gate Rrelease System (WGRS), and related precision airdrop activities within NATO.

\section{Department of Defense JPADS Program Overview}

The purpose of the JPADS is to meet the Combatant Commanders (COCOM) requirement of sustaining combat power using high altitude, precision airdrop as a direct and theater delivery method, into a dynamic, dispersed, and unsecured battlespace. This must be done with speed and flexibility to provide an optional capability previously unavailable to the COCOM, and to enable decisive operational superiority.

JPADS is a family of systems consisting of self guided cargo parachute systems (Army lead), and a common laptop mission planning (MP) and weather system (USAF lead) with numerous additional partners. The JPADS family includes,

- JPADS Extra Light (XL) weight range: 700-2,400 lbs.

- JPADS-Light (L): 5001 lbs-10K lbs: Currently an ACTD.

- JPADS-Medium (M): up to 30K lbs, a US Army Technology Objective (ATO)

- JPADS-Mission Planner (MP):

The JPADS-Mission Planner is a snap-on/snap-off kit for use in C-130s, C-17s, CASAs, and other aircraft to determine optimum Computed Aerial Release Points (CARPs). MP collects and assimilates weather and programs JPADS cargo systems wirelessly in the aircraft just prior to exit. The MP produces JPADS Launch Acceptability Regions (LARs) within which the systems can be dropped to get to their planned Point of Impact (PI) and also wirelessly updates JPADS Airborne Guidance Units (AGUs) with new PIs (if desired) just prior to aircraft exit. The MP is also used for high altitude "dumb" airdrops also known as Improved Container Delivery System (ICDS).

The lead for JPADS requirements is the US Army Combined Arms Support Command (CASCOM). The JPADS Capability Development Document (CDD) for XL \& L increments was approved by the Joint Requirements Oversight Counsel (JROC) on 5 March 2007. Threshold Key Performance Parameters (KPPs) include: Airdrop from $24.5 \mathrm{~K}$ ft Mean Sea Level (MSL) or higher with accuracy within a 150M (2.2Klb) radius (80\% of the time) and

\footnotetext{
${ }^{1}$ All: Warfighter Protection and Aerial Delivery Directorate, AMSRD-NSC-WP-AJ, Kansas St, Natick, MA 01760

2 PM-FSS, Kansas Street, Natick, MA 01760
} 
offsets of at least $8 \mathrm{~km}$. (250M radius for 10Klb variant). US Army Program of Record is lead by USA PM-FSS and a competitive source selection decision was announced on 12 March 2007 for the XL system. All services are partnering on all programs to ensure interoperability, commonality where possible, and to eliminate any duplication of effort and move JPADS forward as rapidly as possible.

\section{JPADS Advanced Concept Technology Demonstration}

The JPADS Advanced Concept Technology Demonstration (ACTD) ${ }^{[1]}$ is the most visible of the JPADS Science and Technology programs and is integrating a USAF developed laptop-computer-based precision airdrop planning system known as the JPADS-MP (Figure 1) with the USA JPADS in the light (L) category of weights (5001-10,000lbs rigged weights) which is currently the 10Klb Screamer system (Figure 2). The integrated system objectives include the ability to airdrop JPADS systems of up to $10,000 \mathrm{lbs}$ rigged weight, from altitudes of up to $25,000 \mathrm{ft}$ mean sea level (MSL) (threshold), with up to $30 \mathrm{kms}$ of horizontal offset (objective), and land precisely within 50meter (objective) of a preplanned ground PI. It is the intent of the JPADS ACTD to demonstrate and assess systems and technologies that can provide a global delivery system capable of 24-hour fort (Continental US locations) to fighter (unit/teams) distribution. Through previous down selections the JPADS-MP and 10K Screamer system are the primary systems being integrated under the ACTD.

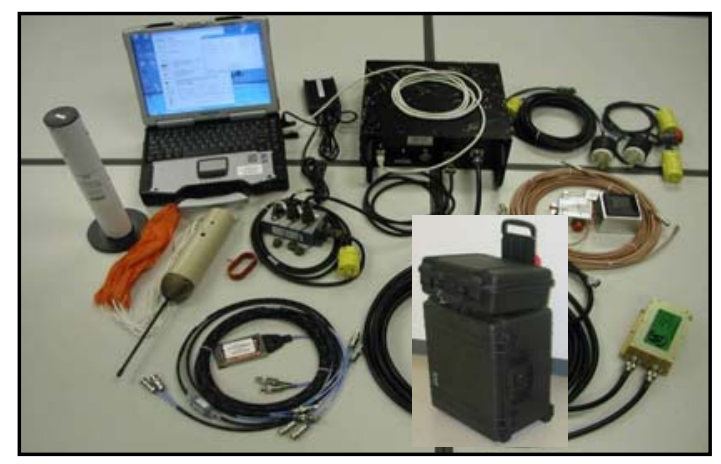

Figure 1. USAF JPADS-MP primary components and carrying case
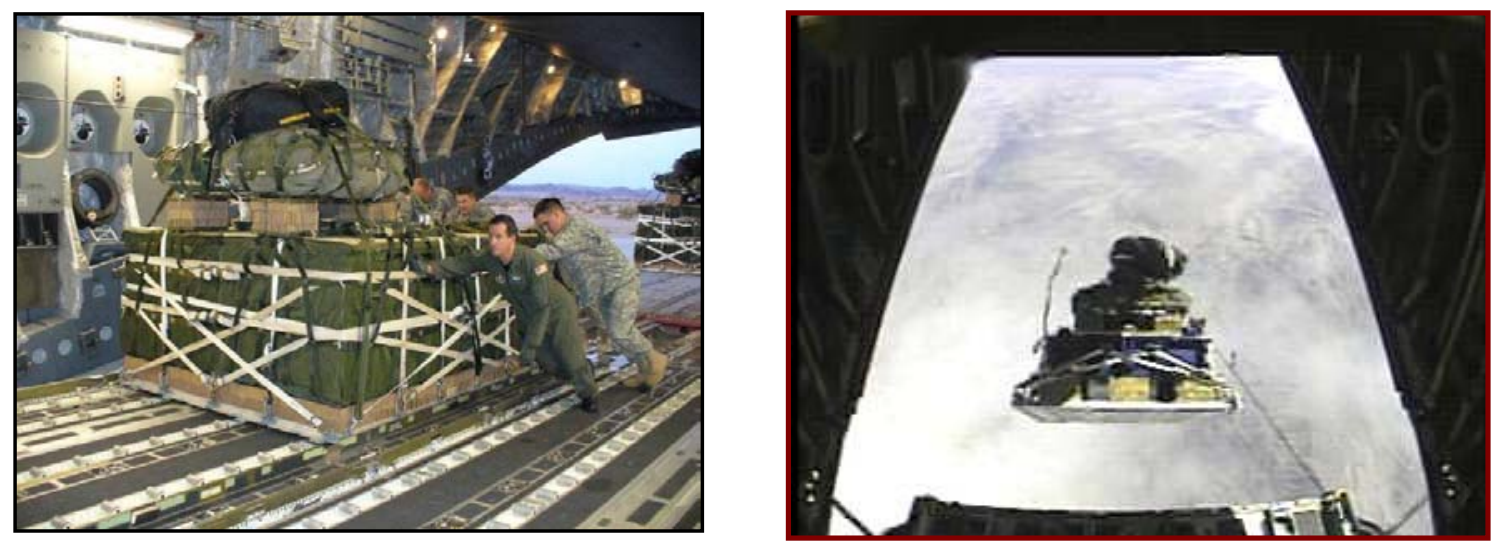

Figure 2. 10K Screamer System being loaded on C-17 (left) and deployed from a C-130 (right)

The JPADS ACTD team conducted the Joint Military Utility Assessment (JMUA) \#2 at the US Army Yuma Proving Ground (YPG), Arizona, from 21 January through 1 February 2007. The assessment focused on how well the system is progressing in meeting the performance criteria established in the JPADS CDD. During JMUA $\# 2$, warfighters demonstrated airdrop resupply missions during operationally realistic events that included parachute packing, rigging, aircraft loading, airdrops, and JPADS component recovery operations. Aircrew members conducted pre-mission and in-flight planning for cargo airdrops from C-130E and C-17 aircraft, which accomplished individual and sequential releases to one or more drop zones. Contractors were permitted to attend and witness all 
activities but only intervened if they saw user errors being made and then addressed these issues with the assessors. JMUA 2 was the second of three planned utility assessments. The JPADS ACTD crawl-walk-run strategy assesses new capabilities under increasingly demanding scenarios after they have first been tested and verified during technical testing events. In JMUA \#1, aircraft released payloads from a single aircraft type $(\mathrm{C}-130 \mathrm{H})$ to a single drop zone (DZ). During JMUA 2, C-130E and C-17 aircraft released payloads individually and sequentially. Operators programmed these payloads to land at multiple drop zones (DZs).

\section{A. JPADS ACTD Technology Overviews:}

JPADS integrates existing hardware and software to develop an autonomously operated gliding system for highly accurate delivery of cargo payloads from high altitudes and large offset distances. The JPADS system-ofsystems consists of two primary subsystems: the 10K SCREAMER decelerator with airborne guidance unit (AGU) and the JPADS Mission Planning System. JPADS is currently using three different government off-the-shelf cargo pallet systems for airdrops.

\section{1) $10 \mathrm{~K}$ SCREAMER Decelerator:}

The 10K SCREAMER (Developed by Strong Enterprises and RoboTek Engineering Inc.) ${ }^{[2]}$ decelerator components (Figure 3) include an 850-square $\mathrm{ft}$ ram air drogue (RAD) that deploys immediately on exit from the aircraft and provides the lift for the system under flight. The system's AGU generates commands to steer the payload to the programmed PI. The 10K SCREAMER decelerator deploys two standard Army G-11 recovery parachutes at approximately $1,100 \mathrm{ft}$ above ground level (AGL) to arrest the forward glide and affect a standard ballistic recovery descent. A 17-foot drogue parachute deploys the G-11 recovery parachutes simultaneously; the drogue parachutes are released by an AGU software command. The G-11 recovery parachutes, which are rigged to a tubular steel frame (recovery mantle), are located directly above the payload. An isolation swivel on the recovery mantle serves as the load sling confluence point.

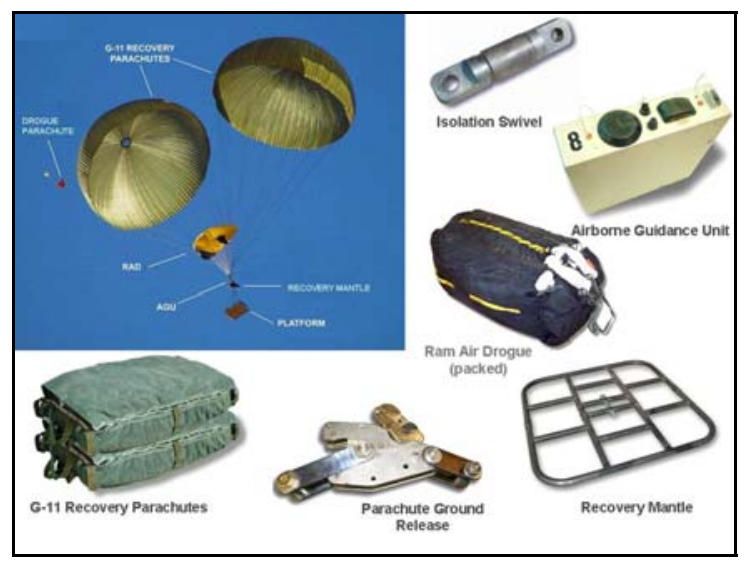

Figure 3. 10K SCREAMER Decelerator Components

The AGU controls the autonomous guided delivery system when released from the air carrier. It uses a Global Positioning System (GPS) and a turn-rate sensor gyro to generate steering commands to direct the system to a waypoint associated with the planned PI. The AGU generates steering commands based on the RAD's current location in relation to the planned PI using current aloft wind profiles. The AGU accomplishes steering using two 1,500-pound (lb) test Spectra steering control lines connected to the suspension lines on the outer edges of the RAD. The AGU is situated on the risers directly beneath the RAD. A completely rigged system of 10K SCREAMER decelerator components weighs a little over $800 \mathrm{lbs}$. An additional feature of the Screamer system is that the AGU can be used on both the $10 \mathrm{Klb}$ and the $2.2 \mathrm{Klb}$ system without modifications. 


\section{2) JPADS Mission Planning System}

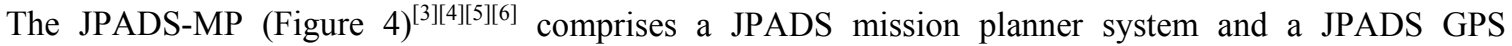
retransmission kit.

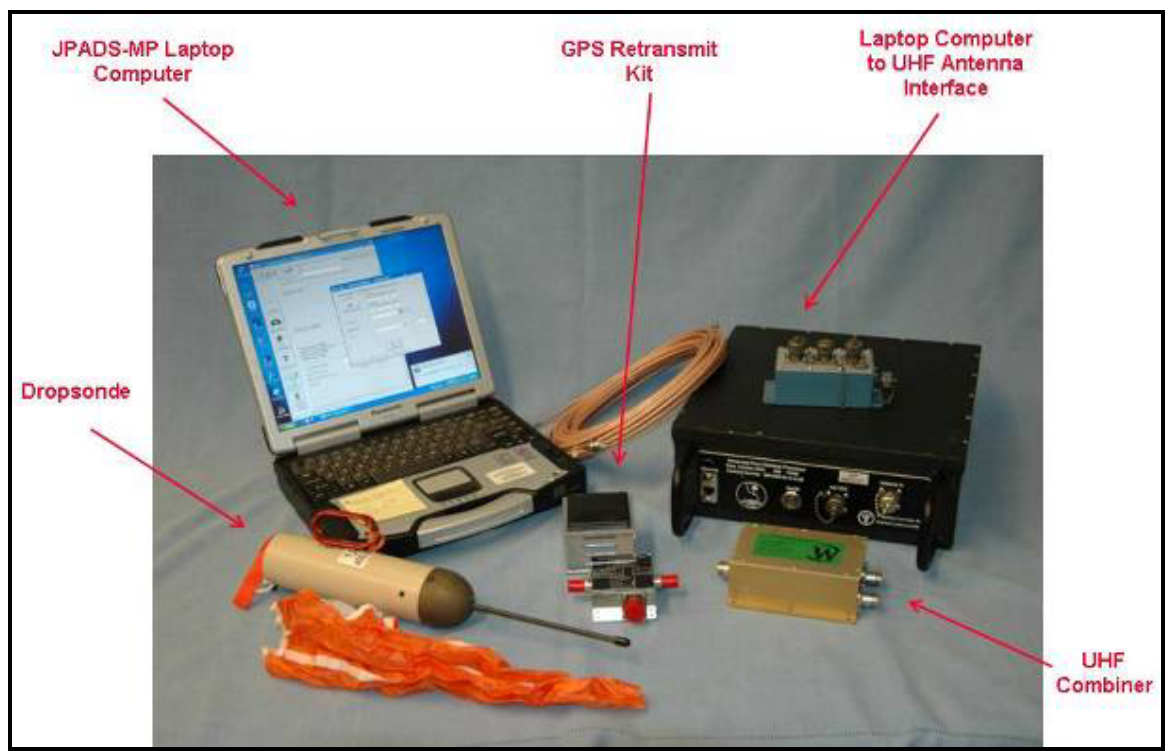

Figure 4. JPADS Mission Planning System

The JPADS-MP software (version 5.1.4) (Developed by Planning Systems Inc., the Charles Stark Draper Laboratory, and the NOAA Earth Sciences Research Laboratory), which runs on a Panasonic CF-29 Toughbook laptop computer, provides the basis to calculate and upload JPADS mission files (pre-mission planning while on the ground and en route on the aircraft) to the AGU. Aircrew members input mission parameters, including forecasted meteorological (MET) data from the Air Force Weather Agency (AFWA), the type of aircraft, the location of the payload on the aircraft, the payload characteristics, and the planned PI, to derive a CARP. The system also has a dropsonde that an aircrew member may deploy from an aircraft prior to an airdrop to collect and transmit aloft wind data back to the JPADS-MP to update the CARP. The system accomplishes in-flight updates to the AGU via an UHF radio link back to the aircraft and the JPADS-MP. The JPADS-MP uses the system's PADS Interface Processor (PIP) and UHF combiner installed on the aircraft for the JPADS laptop computer to receive data from the dropsonde(s).

Aircraft maintainers install a JPADS GPS retransmission kit (wiring, GPS retransmission amplifier, and antenna) in the aircraft designated for the JPADS-MP. These components tap into the aircraft GPS and retransmit the GPS signals in the cargo bay of the aircraft for use by the JPADS AGUs and dropsondes. Both the AGUs and dropsondes require current GPS data before departing the aircraft.

\section{3) ACTD Cargo Pallets}

The JPADS-Light uses three cargo pallets capable of supporting 10K payloads that are compatible with C-130 or $\mathrm{C}-17$ aircraft cargo bays. These cargo pallets include the following:

- The Enhanced Container Delivery System (ECDS) is a multi-modal platform recently type classified by the USA PM-FSS. It has the dimensions of a standard 463-L pallet and weighs $780 \mathrm{lbs}$.

- The fielded 463-L pallet system is made of aluminum skin with a wood or fiberglass core and is framed on all sides by aluminum rails and tie-down rings. The platform is 88 inches by 108 inches (with usable dimensions of 84 by 104 inches) and weighs 355 lbs with nets.

- The fielded Type $\mathrm{V}$ platform is available in a range of lengths from 8 to $32 \mathrm{ft}$. JPADS will use 8 -ft, 820 -lbs and 12-ft, 1,220-lbs versions. The width of the Type V platform, like the $463-\mathrm{L}$ pallet, is 108 inches. The Type $\mathrm{V}$ platform is not compatible with the $\mathrm{C}-17$ logistics rail system. 


\section{B. JMUA \#2}

1) Objectives and Scope:

Marines rigged the airdrop systems while USAF C-130E and C-17 aircrew members planned and executed sorties for 14 airdrop deliveries using the JPADS decelerator systems. The assessment team collected quantitative and qualitative data to address the critical operational issues (COI) and objectives. A minor subset of these $\mathrm{COI} /$ Objectives will be presented below with a summary of the JMUA \#2 results.

\section{COI 1: How well does JPADS successfully support high-altitude offset airdrop missions?}

"The JPADS successfully demonstrated a potential capability to support missions that require payloads to be dropped from high altitudes and large offsets. Warfighters were able to rig, load, plan, deliver, and recover payloads with little assistance from the JPADS instructor team during JMUA \#2. Thirteen of 14 airdrops landed within the JPADS CDD accuracy threshold."

\section{COI 3: Does the JPADS COE provide the Joint Task Force (JTF) commander with an enhanced operational} capability?

"JPADS has the potential to provide the JTF commander with a significant enhancement to current operational capabilities using a system that could keep aircrew members out of the current threat envelope as demonstrated at YPG in a tactical type of environment."

Objective 1.4: Assess the capability of the system to perform payload delivery functions.

"Thirteen of the 14 JMUA \#2 airdrops met the CDD accuracy threshold of a 250-m circular radius of the PI. The systems ranged in weight from 6,900 to $9,900 \mathrm{lbs}$ rigged. Airdrop offset distances were as much as $11.2 \mathrm{~km}$ from altitudes just over 25,000 ft MSL. The aircrew did not identify any new airdrop issues except those typically associated with the burdens of flying missions above $18,000 \mathrm{ft}$ (i.e., concerns of required crew rest cycles, increased onset of crew fatigue, and special personnel [flight physiology] and oxygen equipment requirements). Payloads airdropped during JMUA \#2 included items such as MREs, water in various containers, and ammunition containers (filled with sand) as well as one steel weight tub."

Sub-objective 1.4.2: Assess payload delivery accuracy.

"Thirteen of the 14 airdropped payloads landed within $250 \mathrm{~m}$ of the intended PI (Table 1) meeting the CDD accuracy threshold of $250 \mathrm{~m}$ at an 80 percent probability. Airdropped payloads did not meet the CDD "objective" value of within a 50-m circular radius surrounding the PI at 90-percent probability.“

\begin{tabular}{|c|c|c|c|c|c|c|c|}
\hline $\begin{array}{c}\text { Airdrop } \\
\text { (date/lift } \\
\text { pass/drop) }\end{array}$ & $\begin{array}{l}\text { Delivery } \\
\text { Aircraft }\end{array}$ & $\begin{array}{l}\text { Rigged } \\
\text { weight } \\
\text { (lbs) }\end{array}$ & $\begin{array}{l}\text { Payload } \\
\text { Platform }\end{array}$ & Payload Description & $\begin{array}{c}\text { Airdrop } \\
\text { Altitude } \\
\text { (MSL) }\end{array}$ & $\begin{array}{c}\text { Offset } \\
\text { from PI } \\
(\mathrm{km})\end{array}$ & $\begin{array}{l}\text { Distance to } \\
\text { PI (m) }\end{array}$ \\
\hline $29 / 1 / 2 / 1$ & \multirow{3}{*}{$\mathrm{C}-17$} & 9,900 & $463-\mathrm{L}$ & $\begin{array}{l}\text { Ammunition containers } \\
\text { and MREs }\end{array}$ & 25,025 & 9.8 & 214 \\
\hline $29 / 1 / 4 / 2$ & & 8,500 & $463-\mathrm{L}$ & $\begin{array}{l}\text { Ammunition containers } \\
\text { and MREs }\end{array}$ & 25,171 & 9.8 & 76 \\
\hline $29 / 1 / 6 / 3$ & & 7,500 & 463-L & Ammunition containers & 25,109 & 11.2 & 26 \\
\hline $29 / 1 / 2 / 1$ & \multirow{2}{*}{$\mathrm{C}-130 \mathrm{E}$} & 9,900 & Type V & Water barrels & 19,808 & 7.0 & 198 \\
\hline $29 / 1 / 4 / 2$ & & 9,750 & Type V & Steel weight tub & 19,894 & 7.2 & 84 \\
\hline $31 / 1 / 2 / 1$ & \multirow[b]{2}{*}{$\mathrm{C}-17$} & 7,750 & ECDS & MREs and water jugs & 24,343 & 8.3 & 227 \\
\hline $31 / 1 / 2 / 2$ & & 9,800 & ECDS & $\begin{array}{l}\text { Ammunition containers } \\
\text { and MREs }\end{array}$ & 24,331 & 10.3 & 68 \\
\hline $31 / 1 / 2 / 1$ & \multirow{2}{*}{$\mathrm{C}-130 \mathrm{E}$} & 6,900 & Type V & MREs & 24,335 & 7.8 & 141 \\
\hline $31 / 1 / 2 / 2$ & & 9,800 & Type V & Water barrels & 24,382 & 10.2 & 157 \\
\hline $\mathbf{1} / \mathbf{1} / \mathbf{2} / \mathbf{1}$ & \multirow[b]{2}{*}{$\mathrm{C}-17$} & 7,600 & ECDS & MREs and water jugs & 17,439 & 7.0 & 136 \\
\hline $1 / 1 / 2 / 1$ & & 8,650 & ECDS & $\begin{array}{l}\text { Ammunition containers } \\
\text { and MREs }\end{array}$ & 17,410 & 10.7 & 148 \\
\hline $1 / 1 / 2 / 1$ & \multirow{3}{*}{$\mathrm{C}-130 \mathrm{E}$} & 8,350 & $463-\mathrm{L}$ & Ammunition crates & 17,599 & 5.9 & 335 \\
\hline $1 / 1 / 2 / 2$ & & 7,400 & 463-L & Ammunition containers & 17,555 & 2.7 & 93 \\
\hline $1 / 1 / 2 / 3$ & & 7,400 & $463-\mathrm{L}$ & Ammunition containers & 17,626 & 5.1 & 132 \\
\hline
\end{tabular}

Table 1. Summary of JMUA \#2 10K Screamer drops 
All ground impact points from JMUA \#2 are shown in Figure 5 for each of the 14 airdrops.

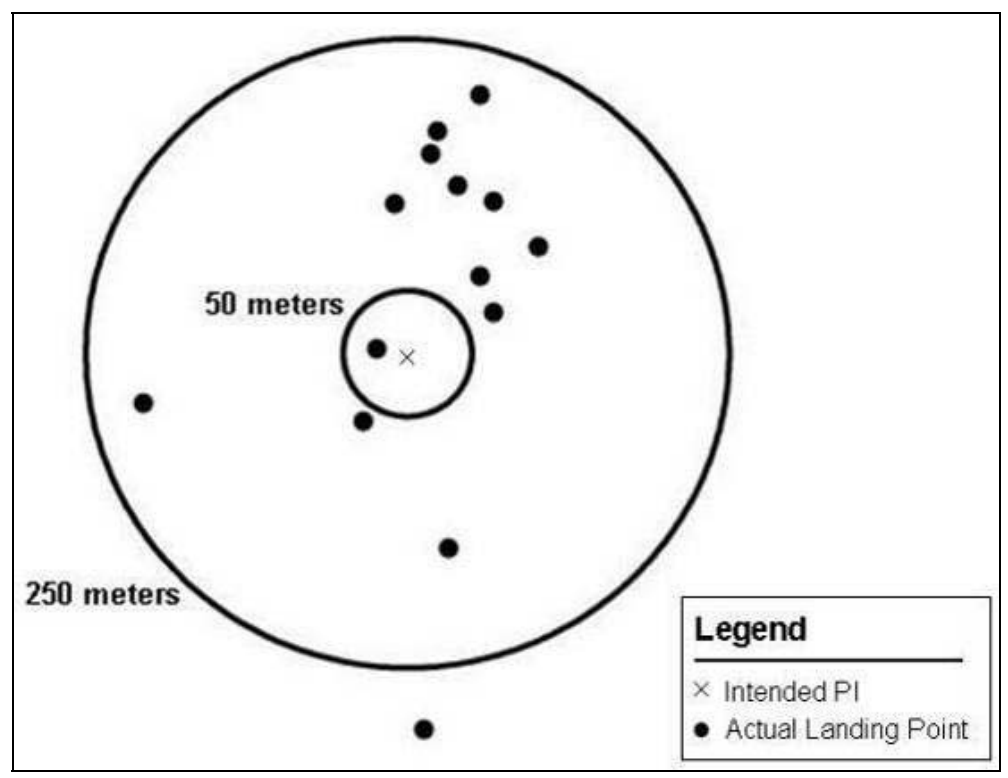

Figure 5. Accuracy Plot of Payload Landing Relative to PI

\section{2) JMUA \#2 Airdrop Details and Trajectory Plots}

Each of the 14 airdrops conducted from 26 January to 1 February 2007 at YPG were analyzed in detail. Tables (such as the one shown in Table 2 from pass 6, drop \# 2) were generated for each airdrop along with trajectory plots as shown in Figure 6. This is a typical trajectory for a Screamer system. Upon exit, the system determines trim and enters a navigation mode to track towards the target, circles the target to a predetermined altitude, and attacks the pickle point, which is just up wind from the PI. At the pickle point, the Screamer system deploys two G-11 round ballistic parachutes for a soft ground impact. Instrumentation to measure opening shocks, rotational rates, trajectories, etc. were also used to collect data on all JMUA \#2 airdrops ${ }^{[7][8]}$.

\begin{tabular}{|c|c|c|c|c|c|}
\hline \multicolumn{6}{|c|}{ Mission } \\
\hline $\begin{array}{c}\text { Date: } \\
\text { 01-29-07 }\end{array}$ & Aircraft: C-17 & Lift: 1 & Pass: 6 & 10K Drop: 3 & AGU: 1014 \\
\hline \multicolumn{3}{|c|}{ Weight (suspended, rigged) } & $6,500 \mathrm{lbs}$ & \multicolumn{2}{|c|}{$7,500 \mathrm{lbs}$} \\
\hline \multicolumn{3}{|c|}{ Payload Dimensions (height, length, width) } & 46 inches & 105 inches & 83 inches \\
\hline \multicolumn{3}{|c|}{ Rigged Dimensions (height, length, width) } & 87.5 inches & 108 inches & 88 inches \\
\hline \multicolumn{3}{|c|}{ Pallet Type and Payload } & $463-\mathrm{L}$ & \multicolumn{2}{|c|}{ Weighted ammunition cans } \\
\hline \multicolumn{3}{|c|}{ Final Planned PI (Corral PI_B) (MSL), (dd.ddddd) } & $1,275 \mathrm{ft}$ & \multicolumn{2}{|c|}{ N 33.3221167, W 114.3646333} \\
\hline \multicolumn{3}{|c|}{ LAR (percent of total capability) } & \multicolumn{3}{|c|}{$100 \%$} \\
\hline \multicolumn{3}{|c|}{ Pre-mission CARP (MSL), (dd.ddddd) } & $24,500 \mathrm{ft}$ & \multicolumn{2}{|c|}{ N 33.3061833, W 114.3679} \\
\hline \multicolumn{3}{|c|}{ In-flight CARP (MSL), (dd.ddddd) } & $24,500 \mathrm{ft}$ & \multicolumn{2}{|c|}{ N 33.2163667, W 114.4024833} \\
\hline \multicolumn{3}{|c|}{ Actual Release Point (MSL), (dd.ddddd) } & $25,109 \mathrm{ft}$ & \multicolumn{2}{|c|}{ N 33.2267583, W 114.4024267} \\
\hline \multicolumn{3}{|c|}{ Aircraft: Airspeed, Deck Angle, and Run-in (mag) } & 145 KIAS & $7 \mathrm{deg}$ & $347 \mathrm{deg}$ \\
\hline \multicolumn{3}{|c|}{ Time Load Departs Aircraft (local) } & \multicolumn{3}{|c|}{ 12:03:45 PM } \\
\hline
\end{tabular}




\begin{tabular}{|c|c|c|}
\hline G-11 Planned Pickle Point (MSL), (dd.ddddd) & $1,775 \mathrm{ft}$ & N 33.32249, W 114.3643 \\
\hline G-11 Actual Pickle Point (MSL), (dd.ddddd) & $2,230 \mathrm{ft}$ & N 33.32199, W 114.3670617 \\
\hline G-11 Pickle Time (local) & & $12: 10: 36$ \\
\hline Time Payload on Ground (local) & & 12:11:01 \\
\hline Actual PI (MSL), (dd.ddddd) & $1,295 \mathrm{ft}$ & N 33.32215, W 114.36491 \\
\hline Ballistic Wind Direction (out of) (mag), Speed & $204 \mathrm{deg}$ & $11.6 \mathrm{kts}$ \\
\hline DZ Wind Direction (out of) (mag), Speed & $60 \mathrm{deg}$ & $1.7 \mathrm{kts}$ \\
\hline $\begin{array}{l}\text { Total Navigation Time: Aircraft Exit to G-11 } \\
\text { Deployment }\end{array}$ & & 0:06:51 \\
\hline Total G-11 Time: G-11 Deployment to on Ground & & 0:00:25 \\
\hline Total Flight Time: Aircraft Exit to on Ground & & 0:07:16 \\
\hline Pickle Point Offset: Pickle Point versus Planned PI & & $226 \mathrm{~m}$ \\
\hline Planned versus Actual G-11 Pickle Point & & $263 \mathrm{~m}$ \\
\hline PI Miss Distance: Planned PI versus Actual PI & & $26 \mathrm{~m}$ \\
\hline CARP Offset: Actual Release Point versus Planned PI & $11.2 \mathrm{~km}$ & $6 \mathrm{~nm}$ \\
\hline
\end{tabular}

Table 2. Sample of table data collected for all JPADS ACTD tests conducted during JMUA \#2

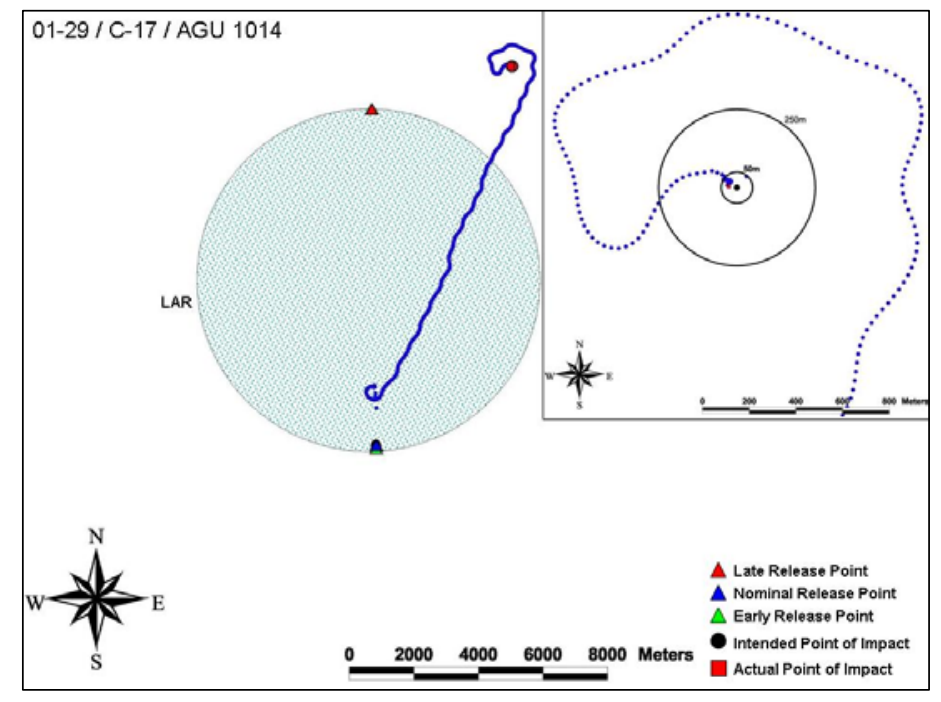

Figure 6. Typical 10K Screamer trajectory (top view) with JPADS-MP LAR computation shown and insert of final approach to the PI

The JPADS ACTD JMUA \#2 demonstrated the overall systems ability to meet the CDD airdrop offset threshold of $8 \mathrm{~km}$ from the intended PI; however, the 25-km offset CDD objective was not met. The maximum airdrop offset of an airdrop was $11.2 \mathrm{~km}$ from its intended PI at an altitude of 25,109 ft MSL (payload landed $26 \mathrm{~m}$ from the intended PI). The lowest airdrop was performed at 17,410 ft MSL. These altitudes met the CDD altitude objectives of delivery from 20,000 to 24,500 ft MSL. Overall, JMUA \#2 achieved the CDD objective of greater than 85 percent payload survivability. Two operational payload images taken just after ground impact are shown in Figure 7. 


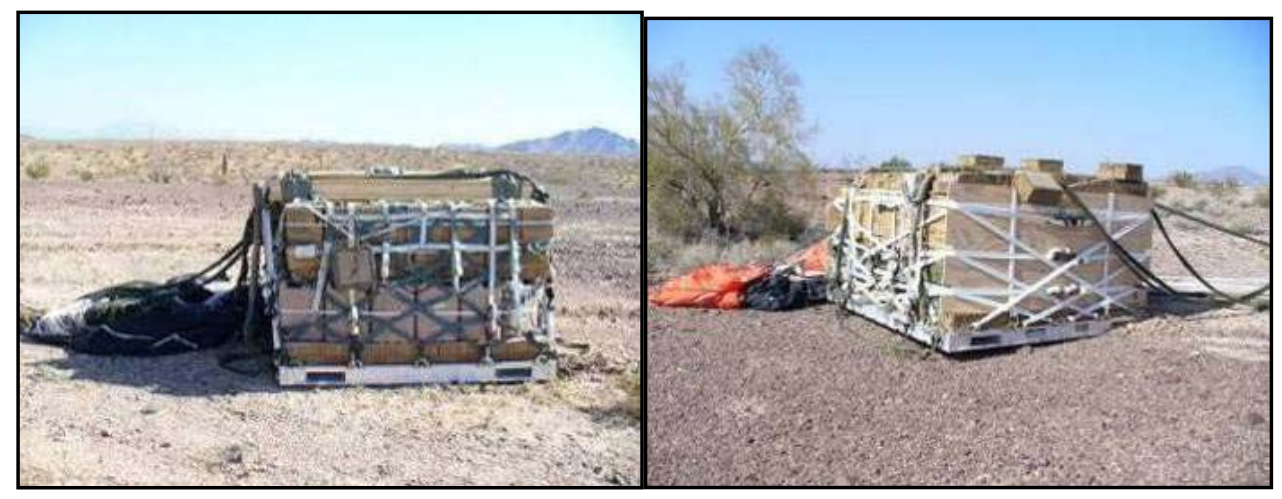

Figure 7. Two operational 10Klb JMUA\#2 payloads just after ground impact

\section{3) Summary of JMUA \#2 and the path forward for the JPADS ACTD:}

C-130E and C-17 aircraft successfully airdropped 14 rigged payloads ranging in weight from 6,900 to 9,900 pounds at altitudes between 17,410 and $25,171 \mathrm{ft}$ MSL and from offsets as far as 11.2 kilometers. All payloads autonomously navigated to the intended drop zones, and 13 of the 14 payloads landed within 250 meters of the desired impact point. Ninety-six percent of the delivered payload contents did not sustain any damage. During JMUA \#2, aircrew members effectively planned pre-mission activities and in-flight missions using the JPADS-MP, and Marine riggers effectively executed rigging for all loads. Warfighters successfully conducted rigging, loading, and recovery operations.

The JPADS ACTD JMUA \# 3 is planned to take place from 7-18 May 2007 at the US Army Yuma Proving Grounds. The ACTD will then enter an Early User Evaluation (EUE) phase in which military participants utilize the residual equipment, to remain current on the capability and continue to evaluate its utility. US Army PM-FSS will likely be issuing a Request for Proposals (RFP) for the JPADS-L weight class during the spring/summer of 2007 and a competitive source selection to determine the system(s) that will enter a formal POR will be selected and matured. Fielding of the final 10K JPADS system is scheduled to begin with first unit equipped in FY10, although rapid combat fielding of the $10 \mathrm{~K}$ Screamer could happen much sooner if the warfighter requests it.

\section{Other Department of Defense JPADS Programs}

\section{A. Formal Army “2Klb” Program of Record:}

In the JPADS-XL weight category (700-2200lbs), the US Army PM-FSS conducted a competitive source selection and has chosen the Para-Flite Firefly system. This system is also being rapidly fielded to a SOCOM user with support from NSRDEC. Figure 8 below shows 3 of 4 Firefly systems dropped in one pass near the PI at YPG just after ground impact. These systems were dropped on 28 February 2007 from 12Kft MSL in support of initial testing for the SOCOM RCF. The impact distances from the PI were (contractor provided data): 8, 12, 13 and 135 meters. The Firefly system began Design Validation (DV) tests during the week of 14 May 2007 and will enter Developmental Testing (DT) in Sept07 and Operational Testing (OT) in Nov07. Additional RCFs of the Firefly system could take place in the near future also. 


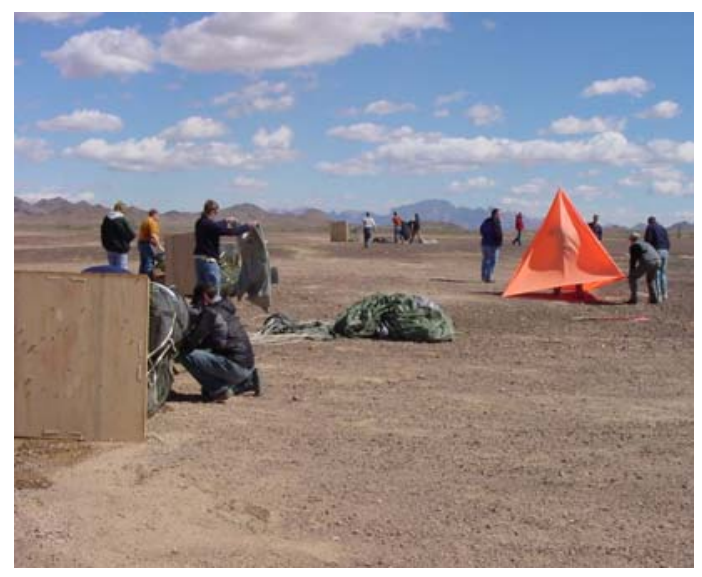

Figure 8. 3 Firefly systems near PI at US Army Yuma Proving Ground just after ground impact.

\section{B. JPADS in current operations through Rapid Combat Fielding (RCF) initiatives:}

In February 2006, the Combined Joint Task Force 76 (CJTF-76) submitted an urgent Operational Need Statement (ONS) for a high altitude precision airdrop capability in theater. Planning toward an early FY07 fielding, the NSRDEC team worked in close coordination with numerous services, test agencies, users, and contractors to transition numerous prototype airdrop systems to the field. Many substantial challenges including finalizing a rapid combat fielding hardware and software configuration and establishing a testing and training plan to include an USAF Flight Test Squadron and Army Test and Evaluation Command (ATEC) Operational Utility Evaluation (OUE) were overcome. To add to the challenges, on 1 July 2006 USAF Senior Leadership requested a condensed schedule to rapidly field in support of Operation Enduring Freedom (OEF) the use of ICDS (Improved Container Delivery System) by 1 August 2006 and JPADS-2K prototypes by 1 September 2006. The ICDS is a standard $26 \mathrm{ft}$ ring slot and G-12 ballistic parachutes when used with the JPADS-MP which substantially increases these systems accuracy from high altitudes. The request included the fielding of the JPADS-Mission Planner and at least ten 2.2Klb. Screamer airdrop systems and $\mathrm{AGAS}^{[9][10][11]}$ (Developed by Capewell Components Inc. and Vertigo Inc.) systems. Both requested dates were met.

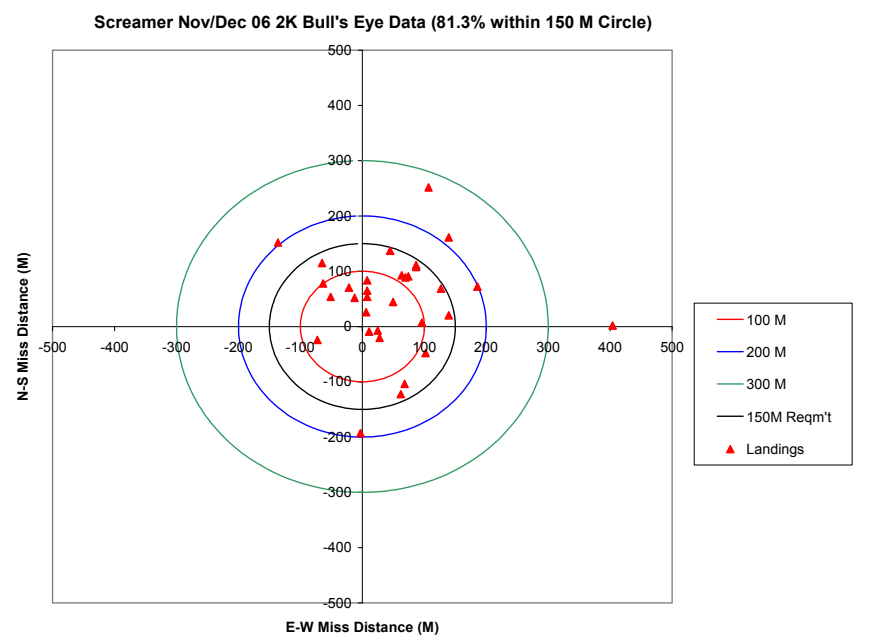

Figure 9. 2.2Klb Screamer data from 2 week OUE at the US Army Yuma Proving Ground in Late CY06

Some of the technical obstacles involved with the fielding were the integration of the Screamer and AGAS systems with the mission planner, ensuring the reliability of the system components, establishing real-time logistics requirements, establishing recovery procedures, and ensuring system capability and reliability when deployed from high altitudes. A lot of software, hardware, logistics and test work were necessary to accomplish the rapid fielding. The first combat "dumb" ICDS airdrop with the JPADS-Mission Planner took place on 29 July 2006. The first 
combat JPADS airdrop was conducted by the US Air Force on 31 August 2006 (Figure 10). Members of the NSRDEC team deployed to the AOR with USAF personnel as part of a mobile training team (MTT) to pack and rig systems for the initial in-theater drops and to provide rigging instruction to the rigger units stationed there. The MTT provided training to all personnel in theater in a train the trainer approach and the USAF MTT flew all combat airdrop missions for well over a month training numerous USAF aircrews. An image of ICDS airdrops and aircrew members observing live dropsonde weather data coming into the JPADS-MP laptop over Afghanistan are shown in Figure 11.

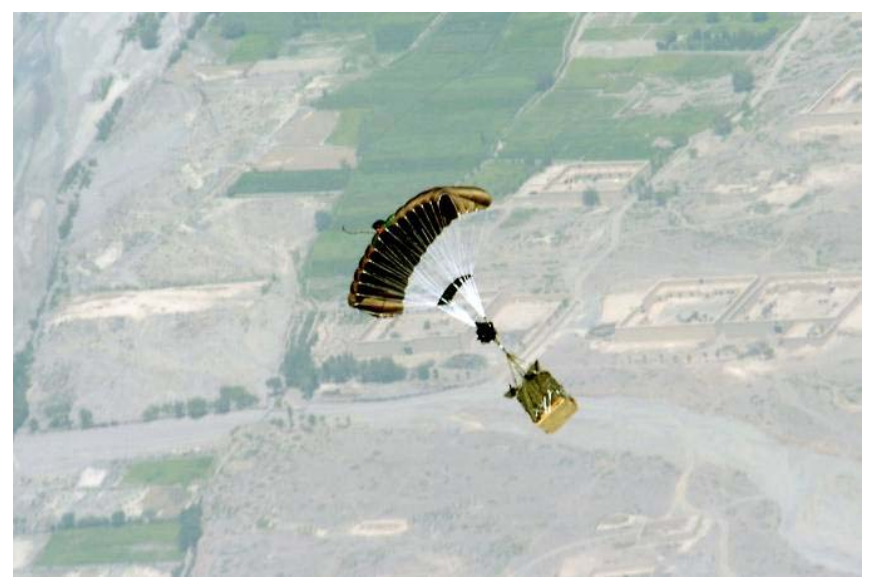

Figure 10. 2Klb capacity SCREAMER system deployed from a USAF C-130 in $1^{\text {st }}$ USAF/USA Combat JPADS airdrop in Afghanistan
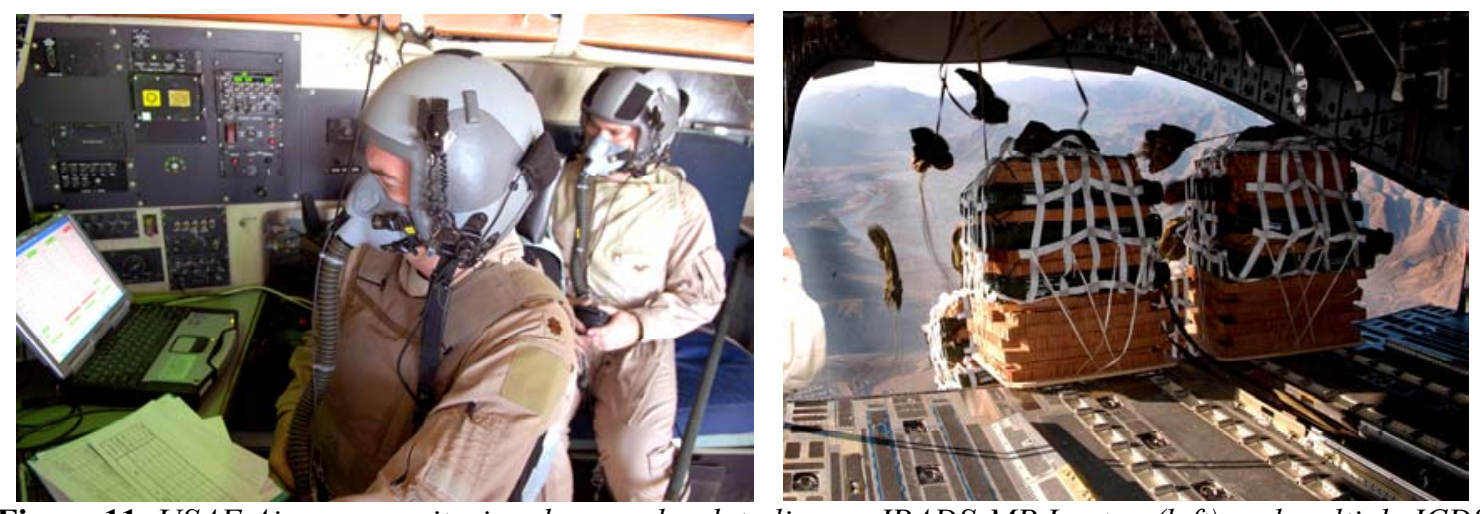

Figure 11. USAF Aircrew monitoring dropsondes data live on JPADS-MP Laptop (left) and multiple ICDS payloads deploying over Afghanistan (right)

Between the time when the JPADS-MP was first employed on 29 July and Dec 2006, over 150 combat airdrops lifts with over 1.2 million pounds of supplies were provided to warfighters that had otherwise very limited means of receiving supplies. With the initial success in Aug and Sept07, and increased warfighter requests for support, the ONS was elevated to a Joint Urgent Operational Need (JUON) with further declaration as an Immediate Warfighter Need (IWN) on 12 September 2006 and funding for 50 additional Screamer systems (requested in the ONS) was provided. The importance of the RCF effort and the JPADS system in general was summarized by commanders in the theater with many positive quotes. These included,

"The employment of Containerized Delivery System (CDS) and JPADS as delivery platforms has proven to be a significant combat multiplier for forces in Afghanistan. Simply put, counterinsurgency operations would not have been possible without this capability. By offsetting over 400 rotary wing sorties or over 200 Combat Logistics patrol Requirements, CDS has saved Soldier's lives (avoiding both Improvised Explosive Devises (IED) and Surface to Air threats) and conserved limited U.S. Resources."

Approval for use of the 50 Screamer systems use by US Army riggers and warfighters on the ground was provided by the Developmental Test Command (DTC) and ATEC based on results of a joint Operational Utility 
Evaluation that was supported by USAF Test and Evaluation Squadron. Figure 10 below shows the 2K Screamer results from the OUE held in late Nov06 over a two week period with 3 C-130 aircraft and numerous aircrew members.

Since 1 January 2007, JPADS ICDS and 2K Screamer systems have been used with increased frequency and have been attributed to saving numerous warfighters lives in Afghanistan. During January and February 2007, nearly 1Mil pounds of resupply was provided to warfighters via JPADS in some of the world's most challenging weather and terrain environments. These combat airdrops include many classes of supplies and have been conducted both for routine and emergency resupply. The impact of these combat resupply missions in OEF as resulted in numerous requests for increased capability: More JPADS as soon as possible. Results of ICDS drops are averaging (Circular Error Average (CEA)) at approximately 230 yards with drops ranging in the 5-7Kft AGL range (this is for the closest bundle in a stick), while JPADS drops at the end of Dec06 were meeting a 240 yard CEA with drops at 10$12 \mathrm{KftMSL}$ and since then, the results have been approximately a 140 yard CEA which includes every drop conducted to date in theater.

\section{Other Complimentary JPADS Programs}

\section{A. Wireless Gate Release System (WGRS)}

For low altitude delivery of CDS sized payloads, having all systems exit the aircraft as quickly as possible is generally the goal to reduce the dispersion of loads on the ground along the direction of aircraft travel. This often results in the loss of some loads due to mid-air contact of containers/parachutes of different systems during openings. This risk is accepted due to the lower cost of the systems and generally low risk to ground personnel due to the low altitude nature of the drops. However, for JPADS CDS drops, the risk of deploying systems immediately after each other is higher. Not only can the systems have collisions during the deployment, but they can also collide during descent as most JPADS do not have knowledge of where other JPADS systems are in the airspace. In addition, JPADS cost significantly more than ballistic (ICDS) systems. An interim capability was rapidly developed to eliminate this issue and is known as the manual gate cut in which the loadmaster manually cuts individual gates for each CDS in a stick with an approximate 3-5 second delay between loads. This method can only be used on 8 CDS within a C-130 (which can hold 16 CDS bundles) due to the space limitations for a loadmaster to physically cut the gates. The capability does not provide the level of flexibility or more specific timing that will enhance JPADS XLs and likely have utility for traditional CDS ballistic systems also.

The technology being investigated is known as a Wireless Gate Release System (WGRS). Wamore Inc. was selected to develop the prototype system which included a Master Control Station (MCS) utilized by the loadmaster which is linked to individual Wireless Gate Release Mechanisms (WGRMs) for each CDS container. The system can be used and testing has begun on both C-130 and C-17 aircraft. Figure 12 shows the MCS unit and a gate release. Figure 13 shows numerous Firefly and other JPADS systems rigged with the releases on a C-17. These Fireflys were dropped on 27 February 2007 with a 3-5 second delay between bundles.
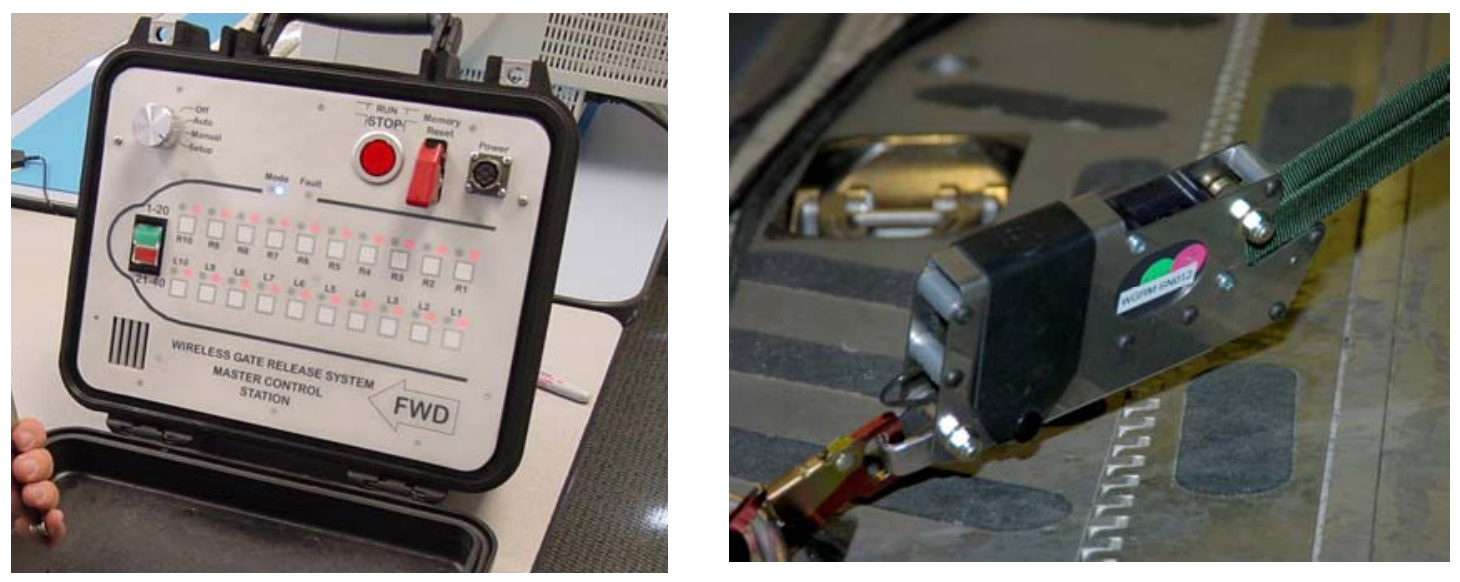

Figure 12. Picture of WGRS MCS (left) and a single WGRM (right) 


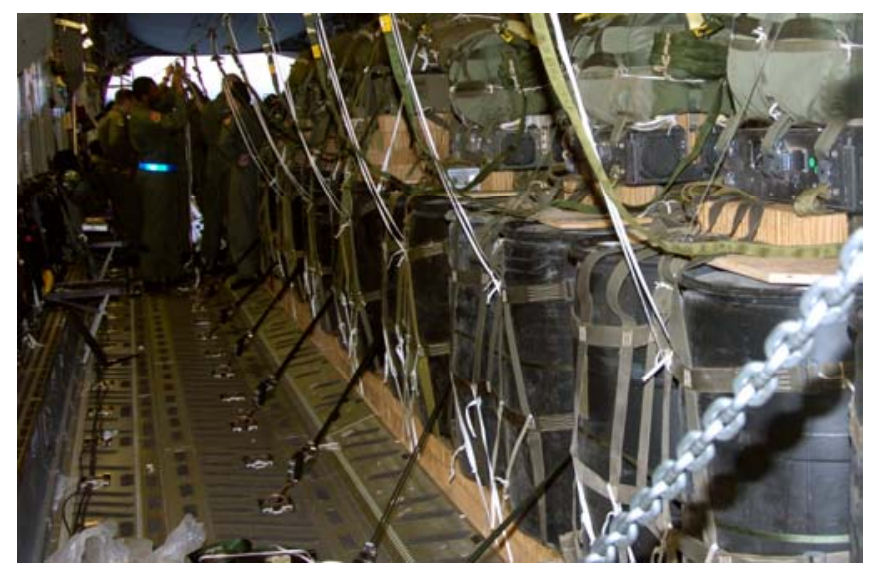

Figure 13. Picture of multiple CDS bundles rigged with WGRS in a C-17 aircraft

Testing to date has used the MCS to activate each installed WGRM by a manual button push by the loadmaster. Tests in the near future will allow the Navigator to plan a pre-determined time delay between each CDS bundle within the JPADS-MP. Release commands will be relayed from the JPADS-MP through the MCS, which will be used by the loadmaster to stop the process only if desired and in case of emergency. The WGRS will therefore allow the Navigator to program the sequence of CDS to be dropped (i.e. which side of the aircraft, how many, etc) and the timing between each load. Since JPADS have the ability to guide themselves to a predetermined PI, the need to have all systems exit the aircraft as quickly as possible is not critical. The WGRS can provide a constant time interval between each CDS or different times for each CDS to maximize its capability and give flexibility to the aircrew. In general, having the heaviest payloads deployed first and keeping a $3+$ second interval between payloads heading to the same PI provides a separation distance (horizontal and vertical combinations) that minimizes the potential for system/system mid-air impacts and potential failures. The capability also allows maximum flexibility to the aircrew for in-flight re-planning and CDS deployment sequencing.

The WGRS will likely be used to improve existing capabilities for ballistic CDS airdrop missions. When deploying CDS to a large force on the ground and over a large DZ, there may be times where providing small groups of CDS along a DZ is more desired than having all CDS deployed at the same CARP. For example, four CDS could be deployed together and then four more CDS a short time later, etc, to provide a full C-130 (16 CDS) to four separate PIs on the DZ. Another example of the WGRS capability is the potential (depending on the wind and load order in the aircraft) to cluster high altitude ICDS bundles together. For example, when the threat at altitude is minimal and the aircrew can chose a run in heading, CDS bundles could be loaded in the aircraft to allow the bundles to be deployed from heaviest to lightest weight. When this is allowable, the aircrew could utilize an in-tothe-wind approach and release the CDS with an optimized time delay between bundles to maximize the potential of a stick of CDS to all land close to the same PI. This capability takes advantage of wind information and would only be applicable to high altitude airdrops. The following simplified example is provided to illustrate this capability. Assuming a C-130 is flying at 140KIAS at an altitude of $25 \mathrm{KftMSL}$ into a "ballistic wind" average to the ground of $20 \mathrm{Kts}$. It is assumed that eight CDS loads $(2200,2100,1800,1700,1600,1200,1000$, and $700 \mathrm{lb}$ respectively) are to be released and are all desired to land at the same PI. The navigator, using the JPADS-MP would compute a CARP for the $1^{\text {st }}$ (heaviest) bundle to be deployed. A relatively simple calculation can be performed to determine the optimum delta time between each load on the remaining lighter-weight CDS to help ensure maximum clustering of all CDS at the desired PI. For this simple case the time deltas between the first and last CDS is 13.41 seconds. A plot of the ideal trajectories (2D) is shown in figure 14 to illustrate the concept. Tests of this concept and future WGRS development is expected to take place through FY08 and beyond. 


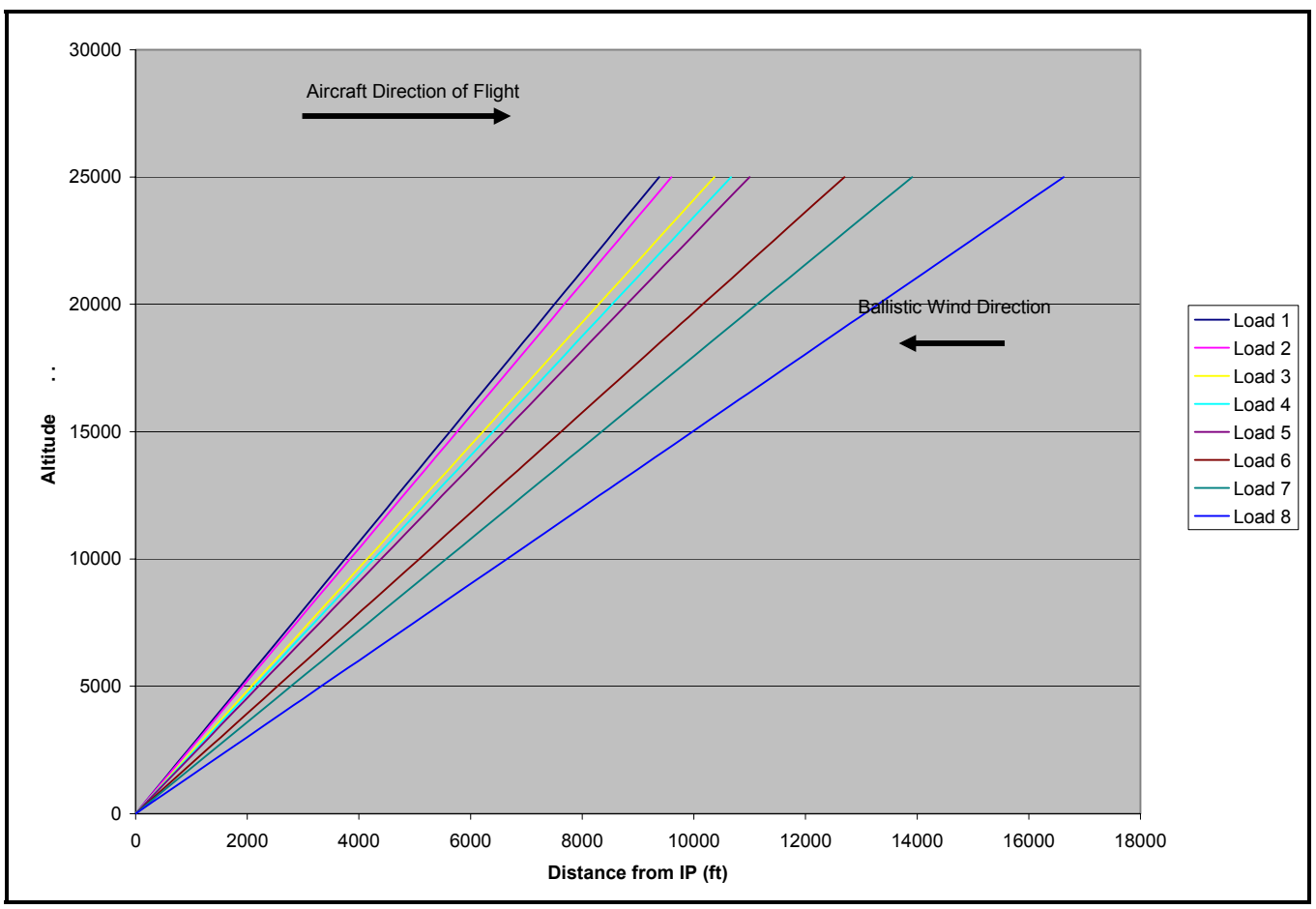

Figure 14. Simple depiction of CDS trajectories with ideal release times between loads for ground impact clustering

\section{B. United States Marine Corps JPADS Ultra-Light Program}

A USMC lead JPADS Ultra Light program is just beginning. This program will likely involve many more DoD organizations and NSRDEC is assisting the USMC and others with the program execution. The desired weight range is 250-700lbs. A variety of commercial off the shelf (COTS) systems are being evaluated to determine there ability to meet the JPADS ultra light requirements. Ultra light systems may be used for resupply but may also be used with follow on military free fall (MFF) paratroopers. The objective is to use existing and soon to be phased out current USMC MFF parachutes on the Ultra Light JPADS systems.

\section{NATO Related Precision Airdrop Activities}

\section{A. Joint precision airdrop capabilities working group activities}

In 2004, the NATO Conference of National Armaments Directors (CNAD) identified ten high priority short term initiatives where improvements were needed for Defense Against Terrorism (DAT). One of the ten short term DAT initiatives identified is "Precision Airdrop for Special Operations Forces," and it is the only DAT for which the U.S. is lead nation. At the CNAD request, the NATO Air Force Armaments Group (NAFAG) was given responsibility for carrying out this initiative. As a result, a NATO ad hoc Joint Precision Airdrop Capabilities Working Group (JPACWG) was formed in September 2004. This working group is chaired by the NSRDEC with support from the USAF, USJFCOM, and other DoD organizations. The aim of the JPACWG is to investigate the technologies which can be used to help define and meet NATO's Precision Airdrop (PAD) capability requirements to fulfill not only the short term DAT, but also a related NATO Long Term Capability Requirement (LTCR).

Within NATO, PAD by definition, includes systems which enable safe and accurate delivery of supplies, equipment, vehicles, and/or personnel from high altitudes (defined by the JPACWG and may differ between Nations) and from a range of transport aircraft and helicopters. These include ballistic and/or autonomous parachute/decelerator systems (over a wide range of payload weights, offset capabilities, and accuracies), mission planning systems, weather forecasting and sensing systems, personnel navigation aids, related integrated communication systems (for use by/with PAD systems), and their linkage and integration into transport aircraft/helicopters.

The specific objectives of the JPACWG include the following: Create a matrix of current national PAD systems and the associated mission areas they support; Create and maintain a PAD Technology Roadmap; Evaluate current and developing National and NATO requirements and Concept of Operations (CONOPS) for PAD; 
Determine potential new technologies and missions to meet new PAD requirements for NATO consideration with other NATO bodies; Assess the need for Technical Standards (STANAG(s)) to support Alliance interoperability and author STANAGs as needed; Conduct a Cost Benefit Analysis of promising technologies to reduce the Life Cycle Cost, supportability, and time to fielding of PAD systems; Execute Precision Airdrop Demonstrations.

Currently, active NATO Nations in the JPACWG and PAD investments include the United States, Canada, France, Germany, Italy, the Netherlands, and the United Kingdom. Some other nations may have and/or may be investing in Commercial Off the Shelf (COTS) PAD items but are not active members of the JPACWG.

\section{B. NATO JPACWG Activities}

A brief description of current JPACWG activities ${ }^{[12]}$ that are geared toward meeting the aforementioned objectives, and provide opportunities for national cooperation follows.

1) Precision Airdrop Technology Conference and Demonstrations (PATCAD):

With support from NATO, the JPACWG assisted the U.S. DoD (NSC) in the execution of international system airdrops at the 2005 Precision Airdrop Technology Conference and Demonstration (PATCAD). This event was held on 17-21 October 2005 at the US Army Yuma Proving Grounds, and was the largest PAD demonstration ever conducted, with over three-hundred-fifty attendees from throughout the world. A final report is available through the author of this paper upon request but has not been formally published. The PATCAD-2003 summary paper is available $e^{[13]}$.

2) $P A C D$ :

On 3-7 July 2006, the JPACWG executed a Precision Airdrop Capability demonstration (PACD) in France. Details on this event will be presented at the $19^{\text {th }}$ AIAA ADS Conference ${ }^{[14]}$.

3) Concept of Operations:

NATO has supported LMI (Logistics Management Institute in the US) to draft a PAD Concept of Operations (CONOPs) which will be published during the summer of 2007 and is being coordinated with all interested NATO Nations and subject matter experts.

4) NATO Industrial Advisory Group Study:

At the JPACWG's request, the NATO Industrial Advisory Group (NIAG) funded a Precision Airdrop Capability (PAC) study to assist NATO in meeting the DAT initiative on "Precision Airdrop Technology for Special Operations Forces" for the NATO Response Force (NRF), and the LTCR on "precision delivery of equipment and supplies by airdrop." The NIAG Sub Group conducting the PAC study is comprised of eighteen Subject Matter Experts (SMEs) from industry representing eight NATO nations, i.e., Germany, Netherlands, Canada, Italy, United Kingdom, Spain, United States, and Turkey. The study's objectives include the following: Analyze existing PAD systems, features, limitations, and work in progress both within and outside NATO; Develop a list/roadmap of contributing/related technologies to assist the JPACWG in prioritizing technological needs; Compile a comprehensive list of testing and training facilities and needs; Conduct an assessment of available weather information/interfacing methods and evolving "state-of-the-art" weather sensing technologies; Identify NATO scenarios and CONOPS. The study's overall goal is to make recommendations for PAD investments by the NATO Nations in order to meet the LTCR. The NIAG invested 200K Euros to conduct the study. This report was completed in Oct06 and provides many suggested technologies worth investigation to improve PAD capabilities.

5) AGARGograph: Airdrop"[15].

The JPACWG supported the publication of an NATO AGARDograph publication titled "Precision

\section{Conclusion}

This paper has provided an overview of some of the DoD's JPADS programs such as the JPADS-L (ACTD), recent Rapid Combat Fielding Initiatives within the JPADS-XL category, and new prototype systems such as the Wireless Gate Release System (WGRS). JPADS decelerator systems within these two weight categories are the most rapidly maturing, needed most by our warfighters, and are of the greatest interest to many NATO Nations and other US Allies.

The JPADS ACTD JMUA \# 2 was conducted during 21 January - 2 February 2007. Both C-130E and C-17 aircraft successfully airdropped 14 rigged Screamer payloads ranging in weight from 6,900 to 9,900 pounds at altitudes between 17,410 and 25,171 ft MSL and from offsets as far as 11.2 kilometers. All payloads autonomously navigated to the intended drop zones, and 13 of the 14 payloads landed within 250 meters of the desired impact point. Ninety-six percent of the delivered payload contents did not sustain any damage. The ACTD is on track for a successful transition to a formal US Army lead Program of Record. 
Many JPADS Rapid Combat Fielding Initiatives took place during CY06 and are on-going in support of the Global War on Terrorism (GWOT). With support and urgent needs submitted from warfighters in theater, numerous JPADS-MPs, a handful of AGAS and numerous $2 \mathrm{~K}$ Screamer systems were rapidly fielded to support OEF. The $1^{\text {st }}$ operational ICDS drop was conducted on 29Jul06 and the $1^{\text {st }}$ combat USAF/USA JPADS drop on 31Aug06. JPADS

is being used to support combat airdrops in OEF (primarily ICDS) often and averaging close to 500,000lbs of resupply per month. JPADS has been recognized for it's enormous and successful impact on the GWOT by senior leaders and been credited with saving warfighters lives in numerous situations since 29 July 2006. This emerging capability is anticipated to grow substantially to protect our valuable aircrew and transport aircraft from low altitude threats while providing an accurate and rapid capability to resupply warfighters on the ground in a variety of environments.

A prototype WGRS has been developed and tested and shows great promises in enhancing JPADS airdrops and utility for other CDS airdrop missions. Continued development and testing is on-going. Many other JPADS programs are beginning such as the USA formal $2.2 \mathrm{~K}$ program of record which will develop and field the firefly system and the USMC who are beginning and ultra light JPADS program.

The paper has also highlighted the need and interest for precision airdrop within NATO Nations and the activities being executed by the Joint Precision Airdrop Capability Working Group in support of NATO requirements. The JPACWG has accomplished a great deal of work and has been complimented by senior NATO leaders. The JPACWG continues to allow for more formal collaborations between NATO Nations with interest in Precision Airdrop and should help ensure that fielded systems are interoperable between Nations.

\section{REFERENCES}

[1] R. Benney, J. Barber, J. McGrath, J. McHugh, G. Noetscher, S. Tavan, "The Joint Precision Airdrop System Advanced Concept Technology Demonstration," AIAA Aerodynamic Decelerator Systems Conference, May 23-26, 2005, Munich, Germany.

[2] J. McGrath, T. Strong, R. Benney, "Status of the Development of an Autonomously Guided Precision Cargo Aerial Delivery System," AIAA Aerodynamic Decelerator Systems Conference, May 23-26, 2005, Munich, Germany.

[3] Philip D. Hattis, Thomas J. Fill, David S. Rubenstein, Robert P. Wright, and Richard J. Benney, "An Advanced On-Board Airdrop Planner to Facilitate Precision Payload Delivery," AIAA Guidance, Navigation, and Control Conference, August 14-17, 2000, Denver, Colorado.

[4] Philip Hattis, Thomas Fill, David Rubenstein, Robert Wright, Richard Benney, David LeMoine, "Status of an On-Board PC-Based Airdrop Planner Demonstration," AIAA Aerodynamic Decelerator Systems Conference, May 22-24, 2001, Boston Massachusetts.

[5] Philip Hattis, Kai Angermueller, Thomas Fill, Robert Wright, Richard Benney, and David LeMoine, "An In-Flight Precision Airdrop Planning System," 23rd Army Science Conference, December 2-5, 2002, Orlando, Florida.

[6] R. Wright, et al, "Precision Airdrop System," AIAA Aerodynamic Decelerator Systems Conference, May 23-26, 2005, Munich, Germany.

[7] G. Noetscher, J. Barber, "Instrumentation for the Assessment of parafoil Performance," AIAA Aerodynamic Decelerator Systems Conference, May 23-26, 2005, Munich, Germany.

[8] G. Noetscher, "Dealing with Noise: A Practical Guide to Collecting Data in Harsh Environments," AIAA Aerodynamic Decelerator Systems Conference, May 22-24 2007, Williamsburg, Virginia.

[9] S. Dellicker, R. Benney, S. Patel, T. Williams, C. Hewgley, P. Yakimenko, R. Howard, and I. Kaminer, "Performance, Control, and Simulation of the Affordable Guided Airdrop System," AIAA Guidance, Navigation, and Control Conference, August 14-17, 2000, Denver, Colorado.

[10] V. Dobrokhodov, O. Yakimenko, I. Kaminer, R. Howard, S. Dellicker, and R. Benney, "Development and Flight Testing of the Affordable Guided Airdrop System for G-12 Cargo Parachute," AIAA Aerodynamic Decelerator Systems Conference, May 22-24, 2001, Boston, Massachusetts. 
[11] B. Gilles, M. Hickey, W. Krainski, "Flight-Testing of a Low-Cost Precision Aerial Delivery System," AIAA Aerodynamic Decelerator Systems Conference, May 23-26, 2005, Munich, Germany.

[12] R. Benney, W. Krainski, Capt Pieter Onckelinx, Capt Cecile Delwarde, Lutz Mueller, Sqd Ldr Mick Vallance, "NATO Precision Airdrop Initiatives and Modeling and Simulation Needs," RTO Applied Vehicle Technology (AVT-133) specialist meeting on Fluid Dynamics of Personnel and Equipment Precision Delivery from Military Platforms, October 2-6 2006, Vilnius, Lithuania.

[13] J. McHugh, R. Benney, J. Miletti, P. Mortaloni, "Planning, Execution, and results of the precision Airdrop technology Conference and Demonstration (2003)," AIAA Aerodynamic Decelerator Systems Conference, May 23-26, 2005, Munich, Germany.

[14] Y. de Lassat de Pressigny, R. Benney, M. Vallance, J. Wintgens, "The Precision Airdrop Capability Demonstration in France," AIAA Aerodynamic Decelerator Systems Conference, May 22-24 2007, Williamsburg, Virginia.

[15] Precision Airdrop, RTO AGARDograph 300 Flight Test Techniques Series - Volume 24, AC/323(SCI-125)TP/125, by Michael R. Wuest and Richard J. Benney, December 2005. 